\title{
Maternal preeclampsia and risk of bronchopulmonary dysplasia in preterm infants
}

\author{
Joyce E. O'Shea' ${ }^{1}$ Peter G. Davis' and Lex W. Doyle'; for the Victorian Infant Collaborative Study Group
}

INTRODUCTION: To better understand whether preeclampsia (PE) increases the risk of bronchopulmonary dysplasia (BPD).

RESULTS: Of 753 infants alive at 36wks, 138 (18.3\%) were exposed to PE. BPD was not significantly related to exposure to PE either before (odds ratio (OR) 0.73; 95\% confidence interval (Cl) $0.50,1.06)$ or after adjustment for confounding variables (adjusted OR 1.14; $95 \% \mathrm{Cl} 0.71,1.81$ ). If infants were selected by gestational age alone, there was no association (OR 1.05; $95 \% \mathrm{Cl} 0.63,1.75)$. In contrast, selecting by birth weight alone, PE was associated with a significant reduction in BPD (OR 0.61, 95\% Cl 0.41, 0.91). However, this effect disappeared after adjustment for confounding variables.

DISCUSSION: Conclusions were unchanged when data from other studies were included in a pooled analysis. PE does not significantly affect the risk of BPD in extremely preterm (EP) or extremely-low-birth-weight (ELBW) subjects.

METHODS: We examined data on EP (<28 wks gestation) or ELBW $(<1,000 \mathrm{~g})$ infants live born in Victoria, Australia, in three eras: 1991-1992, 1997, and 2005. We compared the incidence of BPD (oxygen requirement at 36 wks' postmenstrual age) in the PE group (infants exposed to PE) with that in the remainder (nonexposed infants). We also contrasted results with comparable reported studies.

$\mathbf{P}$ reeclampsia (PE) is a potentially severe complication of pregnancy affecting $2-4 \%$ of pregnancies $(1,2)$. The condition frequently necessitates preterm delivery for both maternal and fetal reasons (3). Bronchopulmonary dysplasia (BPD) is a common complication of extremely preterm (EP, $<28 \mathrm{wks})$ birth that persists despite improvements in perinatal care, including antenatal corticosteroids (4) and exogenous surfactant (5).

Several studies have examined the relationship between intrauterine exposure to maternal $\mathrm{PE}$ and the risk of the infant developing BPD (6-12). Some of these report that PE is protective and reduces the incidence of BPD $(9,10,12)$. Others report that $\mathrm{PE}$ is associated with an increased incidence of $\operatorname{BPD}(7,8)$. Still others have found no change $(6,11)$.

We sought to clarify the association between maternal PE and BPD in three large geographical cohorts of EP/extremely- low-birth-weight (ELBW, <1,000 g birth weight) infants born in the post-surfactant era.

RESULTS

The three Victorian Infant Collaborative Study cohorts combined totaled 1,268 live-born infants who were either EP or ELBW, 575 (40.6\%) of whom were excluded as they did not survive to $36 \mathrm{wks}$ ' corrected gestation. This yielded a study sample of 753 infants who were EP or ELBW, 138 (18.3\%) of whom were born to mothers with PE; there were two mothers in whom it was unclear if they had PE or not. An ultrasound before 20 wks was obtained in $90.2 \%(620 / 687)$ of cases with data; data on early ultrasounds were missing in 66 cases. In only two infants was there a discrepancy in dates between the best obstetric estimate of postmenstrual age (PMA) and a pediatric estimate after birth.

On variables determined antenatally, the mothers who had PE were more likely to be primigravida and be delivered by cesarean section, and were less likely to have prolonged rupture of the membranes; their infants were more likely to be female, more mature, but lighter at birth, and therefore were more likely to be small for gestational age, but they were less likely to be male or part of a multiple birth (Table 1).

The overall incidence of BPD in the PE group was 37.7\% (52/138), lower than the rate of $45.7 \%(279 / 611)$ in the non-PE group, a nonsignificant difference (odds ratio (OR) 0.73; $95 \%$ confidence interval (CI) $0.50,1.06 ; P=0.10$ ) (Table 2; Figure 1). The effects were similar within the three separate Victorian Infant Collaborative Study cohorts $\left(I^{2}=0\right.$; Figure 1$)$. Several other perinatal variables that were determined by the time of birth were significantly associated with BPD, including rupture of the membranes for $>24 \mathrm{~h}$ before delivery, vaginal delivery, male sex, not being growth-restricted at birth, and lower birth weight and gestational age (Table 2). When these were entered into a logistic regression analysis, only male gender, lower birth weight, and gestational age were significantly associated with BPD. After adjusting for these confounding variables, there was no association between $\mathrm{PE}$ and $\mathrm{BPD}$ (Table 2).

When the subjects were selected by gestational age $<28 \mathrm{wks}$ alone, $11.9 \%(68 / 570)$ of infants were born to mothers with 


\section{\begin{tabular}{l|l} 
o'Shea et al. & Articles
\end{tabular}}

Table 1. Perinatal features contrasted between infants whose mothers had PE and those who did not

\begin{tabular}{|c|c|c|c|c|}
\hline Variable & $\mathrm{PE}(N=138)$ & No PE $(N=613)^{a}$ & Statistics & $P$ value \\
\hline Primigravida mother, $\%(n)$ & $49.3(68)$ & $35.8(70)^{b}$ & $1.74(1.20,2.53)^{c}$ & 0.004 \\
\hline Antenatal corticosteroids, $\%(n)$ & $83.3(115)$ & $82.1(501)^{d}$ & $0.92(0.56,1.50)^{c}$ & 0.74 \\
\hline Multiple birth, \% (n) & $8.7(12)$ & $29.5(181)$ & $0.23(0.12,0.42)^{c}$ & $<0.001$ \\
\hline Cesarean delivery, \% ( $n$ ) & $92.0(127)$ & $44.9(275)$ & $14.2(7.51,26.8)^{\mathrm{c}}$ & $<0.001$ \\
\hline Gestational age (completed wks), mean (SD) & $27.8(1.7)$ & $26.3(1.9)$ & $1.4(1.1,1.8)^{f}$ & $<0.001$ \\
\hline Birth weight (g), mean (SD) & $814(145)$ & $872(174)$ & $-59(-90,-28)^{f}$ & $<0.001$ \\
\hline Birth weight $Z$ score $<-2$ SD, $\%(n)$ & $39.1(54)$ & $11.7(72)$ & $4.83(3.17,7.36)^{c}$ & $<0.001$ \\
\hline
\end{tabular}

Table 2. Perinatal features contrasted between infants who had BPD and those who did not

\begin{tabular}{|c|c|c|c|c|c|c|}
\hline Variable & $\begin{array}{c}\text { BPD } \\
(N=332)\end{array}$ & $\begin{array}{l}\text { No BPD } \\
(N=419)^{\mathrm{a}}\end{array}$ & $\begin{array}{l}\text { Univariable } \\
\text { analysis }\end{array}$ & $P$ value & $\begin{array}{c}\text { Multivariable } \\
\text { analysis, OR }(95 \% \mathrm{Cl})\end{array}$ & $P$ value \\
\hline Primigravida mother, $\%(n)$ & $39.9(132)^{b}$ & $37.0(155)$ & $1.13(0.84,1.52)^{c}$ & 0.42 & & \\
\hline Membranes ruptured $>24 \mathrm{~h}, \%(n)$ & $25.4(83)^{d}$ & $17.5(83)^{b}$ & $1.61(1.13,2.29)^{c}$ & 0.008 & $1.31(0.88,1.95)$ & 0.18 \\
\hline Multiple birth, \% (n) & $25.6(85)$ & $25.8(108)$ & $0.99(0.71,1.38)^{c}$ & 0.96 & & \\
\hline Male sex, \% (n) & $57.2(190)$ & $42.5(178)$ & $1.81(1.35,2.42)^{c}$ & $<0.001$ & $1.88(1.36,2.59)$ & $<0.001$ \\
\hline Gestational age (completed wks), mean (SD) & $25.9(1.7)$ & $27.2(2.0)$ & $-1.3(-1.6,-1.0)^{\mathrm{e}}$ & $<0.001$ & $0.70(0.60,0.82)^{f}$ & $<0.001$ \\
\hline Birth weight (g), mean (SD) & $810(176)$ & $903(154)$ & $-93(-116,-69)^{\mathrm{e}}$ & $<0.001$ & $0.80(0.71,0.91)^{g}$ & $<0.001$ \\
\hline Birth weight $Z$ score $<-2$ SD, $\%(n)$ & $13.0(43)$ & $20.0(84)$ & $0.59(0.40,0.88)^{c}$ & 0.01 & $1.43(0.73,2.80)$ & 0.30 \\
\hline
\end{tabular}

$\mathrm{BPD}$, bronchopulmonary dysplasia; $\mathrm{Cl}$, confidence interval; OR, odds ratio.

${ }^{a} n=2$ missing data. ${ }^{b} n=1$ missing data. ${ }^{c} \mathrm{OR}(95 \% \mathrm{Cl}) .{ }^{\mathrm{d}} n=5$ missing data. ${ }^{\mathrm{e}}$ Mean difference $(95 \% \mathrm{Cl}) .{ }^{\mathrm{f}}$ Per one-week increase. ${ }^{9} \mathrm{Per} 100-\mathrm{g}$ increase.

$\mathrm{PE}$; there was no significant relationship between $\mathrm{PE}$ and $\mathrm{BPD}$, which was consistent across the three individual eras (Figure 1). This conclusion was not altered after adjusting for confounding variables (adjusted OR 1.20, 95\% CI 0.64, 2.23, $P=0.57$ ).

Selecting the subjects by birth weight $<1,000 \mathrm{~g}$ alone, $21.6 \%$ $(133 / 616)$ of infants were born to mothers with PE, which was strongly associated with a lower rate of BPD, a consistent observation across the three individual eras (Figure 1). However, after adjustment for confounding variables, the association between PE and BPD disappeared (adjusted OR 1.10, 95\% CI 0.67, 1.80, $P=0.70$ ).

The literature review found seven similar studies (6-12). These are summarized in Table 3. On reading the methods in all studies, four were subsequently rejected. In one study, the cohort was born before 1991 and BPD was determined at 28 days only (12). In another study of infants $<1,501 \mathrm{~g}$ birth weight from a single hospital, it was not possible to reconstruct data for the outcome of BPD at 36 wks' PMA, although there was a nonsignificant reduction in the risk of BPD at 28 days in those whose mothers had PE (risk ratio $0.71 ; 95 \%$ CI $0.39,1.27)(10)$. One study was excluded because it was a casecontrol study and not a cohort study (9); in this study, there was a nonsignificant reduction in the odds of BPD with exposure to PE (OR $0.89,95 \%$ CI $0.28,2.81$ ). In the fourth study, of 107 infants 23-32 wks' gestation from a single center in the United States, it was unclear how many of the subjects were alive at 36 wks' PMA, and hence it was not possible to calculate a correct denominator (8); this study reported an increased risk of BPD with exposure to PE (OR 2.96, 95\% CI 1.17, 7.51).

Of the remaining three studies $(6,7,11)$, all defined BPD as oxygen dependency at $36 \mathrm{wks}$ (one also included $\mathrm{X}$-ray changes) (6), all had high rates of antenatal corticosteroid administration, and all had those alive at $36 \mathrm{wks}$ PMA as the denominator for the rate of BPD; however, unlike the Victorian data, none were from geographical cohorts. One study selected 371 infants either $<32 \mathrm{wks}$ or $<1,500 \mathrm{~g}$ birth weight from a single center born in the 1990s and found no relationship between PE and BPD at 36 wks (risk ratio $1.03,95 \%$ CI $0.70,1.52)(11)$. One study of 306 infants $<30$ wks from two centers in the United States, born largely in the 1990s, found no significant relationship between PE and BPD (risk ratio 1.06, 95\% CI 0.72, 1.55) (6). The largest study was of 1,241 infants $<28$ wks' gestation from 14 centers in the United States. This study excluded 12\% of eligible infants for whom parental consent was not obtained (7). In addition, BPD data were not available for 10 subjects; this 


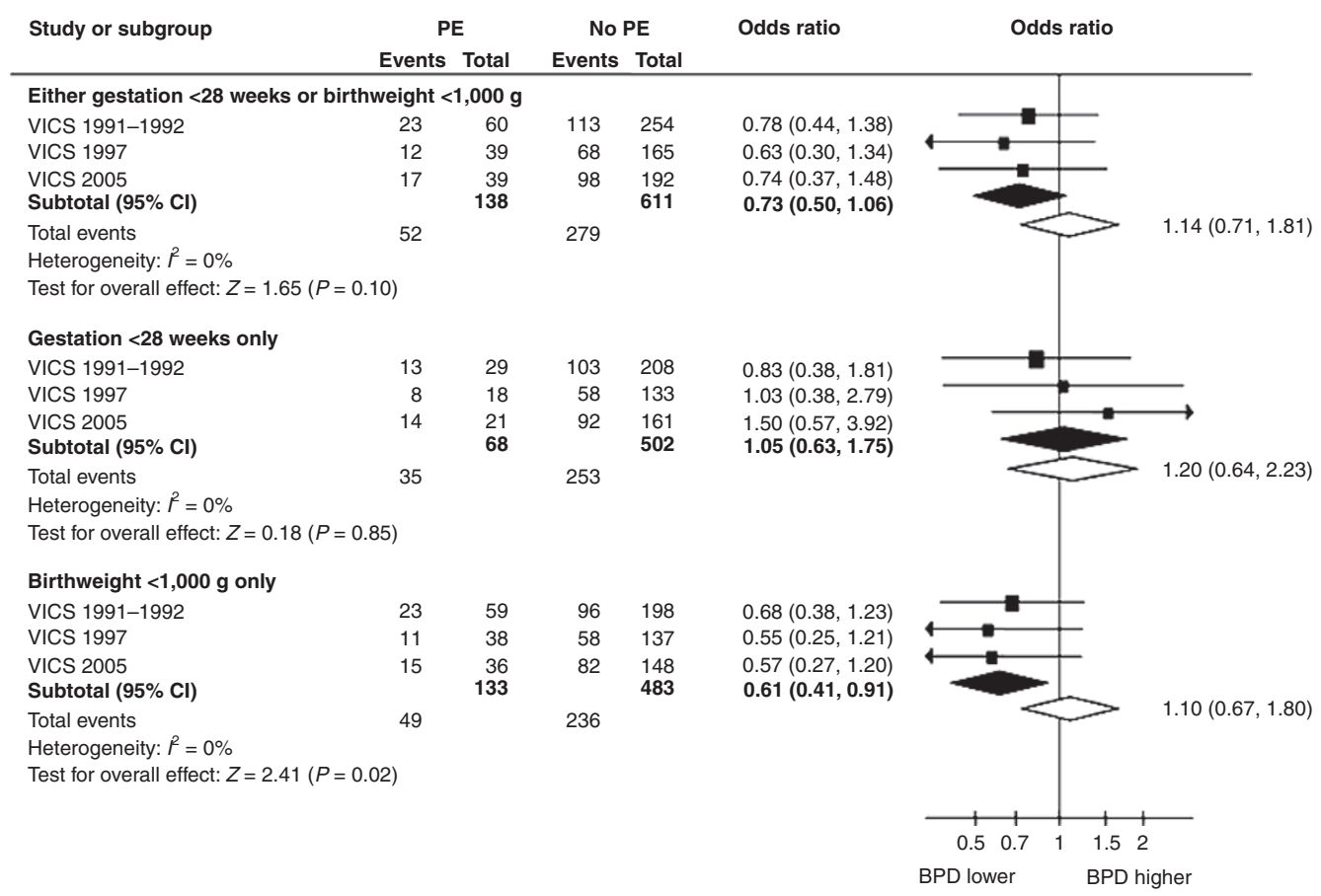

Figure 1. Forest plot of risk of BPD in relation to exposure to PE in Victorian cohorts, selected according to different criteria. Results adjusted for confounding antenatal variables are shown as open diamonds, with adjusted odds ratios and $95 \%$ Cls to the right of the diamond. BPD, bronchopulmonary dysplasia; $\mathrm{Cl}$, confidence interval; $\mathrm{PE}$, preeclampsia.

study found a significantly higher rate of BPD with PE (risk ratio $1.29,95 \%$ CI 1.14, 1.47).

It was possible to perform a pooled analysis of studies where infants were selected by gestational age. This included our study and those of Khan et al. (6) and Bose et al. (7). The analysis showed moderate heterogeneity $\left(I^{2}=49 \%\right)$ and a nonsignificant increased risk of BPD with exposure to PE (OR 1.37, 95\% CI $0.91,2.04, P=0.13$, random effects model, 3 studies, 2,117 subjects). It was possible to combine our data for meta-analysis selected by both birth weight and gestational age with Redline et al. (11), which revealed little heterogeneity $\left(I^{2}=16 \%\right)$, and a nonsignificant reduced risk of BPD with exposure to PE (OR 0.81, 95\% CI 0.59, 1.11, fixed effects model, $P=0.18,2$ studies, 1,120 subjects). There were no other studies with the cohort selected by birth weight only with which we could combine our data.

\section{DISCUSSION}

In our EP/ELBW cohorts, the conclusions concerning the risk of BPD in relation to exposure to $\mathrm{PE}$ were influenced by the way the cohort was selected. Cohorts were defined in three different ways-by gestation, by birth weight, or by a combination of both. Our Victorian data allowed us to determine results for all three definitions. Comparison by gestational age is only possible if the gestational age is accurately assessed. In Victoria, the vast majority of mothers have an ultrasound to confirm dates early in pregnancy (13); therefore it is possible to select cohorts based on gestation. When reported by either gestation $<28 \mathrm{wks}$ or birth weight $<1,000 \mathrm{~g}$, there was a nonsignificant reduction in the risk of BPD. On the other hand, if selected by birth weight only, there was a significant reduction in risk, which disappeared when corrected for confounding variables. When selected by gestational age only, there was no significant relationship between PE and BPD, which did not change when corrected for confounding variables.

It is interesting that the effect of PE on BPD changes so dramatically on redefining the cohorts. The most likely explanation may be related to $\mathrm{PE}$ as a cause of intrauterine growth restriction, a well recognized complication of PE (14), and an association observed in our study. More mature growth-restricted infants may be protected by their more advanced gestation and may be therefore less likely to develop BPD. Selecting cohorts by birth weight alone is problematic, with an overrepresentation of growth-restricted infants, whereas selection of cohorts by gestational age is preferable when trying to establish the influence of fetal growth restriction on outcomes (15). The current study illustrates the problem of selecting cohorts by birth weight alone, which would lead to the false conclusion that $\mathrm{PE}$ is protective against $\mathrm{BPD}$, if not adjusted for other confounding antenatal variables.

There were many differences in variables determined antenatally in infants where the pregnancy was complicated by PE as compared with those where it was not (Table 1), including having a primigravida mother, no prolonged rupture of the membranes, being a singleton birth, being delivered by cesarean section, being female, being more mature but lighter at birth, and hence being more growth-restricted. Of these variables, several were associated with BPD, but only being male, and being smaller and lighter at birth were associated with BPD in the multivariable logistic regression; after adjusting for these significant variables, there was no association between $\mathrm{PE}$ and $\mathrm{BPD}$, regardless of which way the cohorts were selected. 
Table 3. Details of studies reporting risk of BPD in relation to exposure to PE

\begin{tabular}{|c|c|c|c|c|c|c|c|}
\hline Study & Site & Years of birth & $\begin{array}{l}\text { Inclusion/exclusion } \\
\text { criteria }\end{array}$ & BPD definition & Denominator & $\begin{array}{l}\text { Antenatal } \\
\text { corticosteroids }\end{array}$ & $\begin{array}{l}\text { Sample } \\
\text { size }\end{array}$ \\
\hline 6 & $\begin{array}{l}\text { Two centers (Philadelphia, } \\
\text { PA-hospital A and } \\
\text { Toledo, } \mathrm{OH} \text {-hospital B) }\end{array}$ & $\begin{array}{l}\text { 1993-1997 } \\
\text { (hospital A); } \\
1997-2000 \\
\text { (hospital B) }\end{array}$ & $<30$ wks & $\begin{array}{l}\text { Oxygen at } 36 \text { wks } \\
\text { and chest X-ray } \\
\text { changes }\end{array}$ & $\begin{array}{l}\text { Alive at } \\
36 \mathrm{wks}\end{array}$ & $\begin{array}{l}73 \% \text { hospital A, } \\
69 \% \text { hospital B }\end{array}$ & 306 \\
\hline 7 & $\begin{array}{l}14 \text { centers, } \\
\text { United States }\end{array}$ & 2002-2004 & $\begin{array}{l}<28 \text { wks, informed } \\
\text { consent; } 10 \text { with no } \\
\text { BPD data excluded }\end{array}$ & Oxygen at 36 wks & $\begin{array}{l}\text { Alive at } \\
36 \mathrm{wks}\end{array}$ & $90 \%$ & 1,241 \\
\hline $9^{a}$ & $\begin{array}{l}\text { Single center } \\
\text { (Providence, RI) }\end{array}$ & 1991-1992 & $\begin{array}{l}<1,251 \mathrm{~g} \text { birth weight } \\
\text { and }<33 \text { wks }\end{array}$ & Oxygen at 36 wks & $\begin{array}{l}\text { Alive at } \\
36 \text { wks }\end{array}$ & No data & $\begin{array}{l}\text { Cases (PE) } \\
35, \text { controls } \\
\text { (no PE) } 70\end{array}$ \\
\hline $10^{\mathrm{b}}$ & $\begin{array}{l}\text { Single center } \\
\text { (Tampere, Finland) }\end{array}$ & 1990-1994 & Birth weight $<1,501 \mathrm{~g}$ & $\begin{array}{l}\text { Oxygen at } 28 d \\
\text { and chest X-ray } \\
\text { changes }\end{array}$ & Alive at $28 \mathrm{~d}$ & $37 \%$ & 192 \\
\hline $12^{\mathrm{d}}$ & $\begin{array}{l}\text { Single center } \\
\text { (Farmington, CT) }\end{array}$ & 1984-1990 & $\begin{array}{l}\text { Singletons } 500-1,499 \mathrm{~g} \\
\text { birth weight and } \\
\text { gestation } 24-36 \text { wks }\end{array}$ & $\begin{array}{l}\text { Oxygen at } 28 \mathrm{~d} \\
\text { and chest X-ray } \\
\text { changes }\end{array}$ & All live births & No data & 535 \\
\hline $\begin{array}{l}\text { Current } \\
\text { study }\end{array}$ & $\begin{array}{l}\text { Geographical } \\
\text { cohorts } \times 3 \text {, Victoria, } \\
\text { Australia }\end{array}$ & $\begin{array}{l}\text { (i) } 1991-1992 \\
\text { (ii) } 1997 \\
\text { (iii) } 2005\end{array}$ & $\begin{array}{l}<28 \text { wks or }<1,000 \mathrm{~g} \\
\text { birth weight }\end{array}$ & Oxygen at 36 wks & $\begin{array}{l}\text { Alive at } \\
36 \text { wks }\end{array}$ & $\begin{array}{l}\text { (i) } 73 \% \\
\text { (ii) } 88 \% \\
\text { (iii) } 89 \%\end{array}$ & $\begin{array}{l}\text { (i) } 314 \\
\text { (ii) } 206 \\
\text { (iii) } 233\end{array}$ \\
\hline
\end{tabular}

BPD, bronchopulmonary dysplasia; PE, preeclampsia.

aExcluded as case-control study. ${ }^{\mathrm{b} C}$ Cannot reconstruct 36-wk data-appears to be underreporting of PE rate in no-BPD group. ${ }^{\complement}$ Excluded as unclear how many alive at 36 wks and thus could not determine correct denominator. 'Excluded as BPD defined at $28 \mathrm{~d}$ and before 1990.

Our cohort is made up of a combination of patients from three separate time periods since 1991, and we considered that changes in neonatal care over this time period might alter the relationship between PE and BPD. We therefore analyzed each of the three eras separately and found the results were consistent over the three separate eras, with no evidence of heterogeneity.

When our results were combined with previously published reports, the conclusions remained unchanged. Of the other studies that were ultimately included in the meta-analysis, the definition of PE varied, from definitions similar to ours $(6,7)$ to no definition at all (11). The total number of subjects in these combined studies was large, and hence the results are likely to be robust.

The strength of our study is that it is a large multicenter study from the same geographical area. The previous studies are either single-centered (8-12) or multicentered $(6,7)$, but none is based on a geographical cohort. A weakness of our study is that we cannot be certain about the biochemical abnormalities that led to a diagnosis of PE in the mother, but we do know it had to be severe enough to lead to early delivery.

This study clarifies the association of PE and BPD and helps to explain why previous studies have reported apparently contradictory results. We conclude that exposure to PE has little effect on the risk of developing BPD. What remains to be determined, and is arguably more important, is whether PE has any important influences on health beyond the nursery into later life, regardless of the effects it might or might not have on BPD.

\section{METHODS}

\section{Subjects}

The subjects comprised EP or ELBW infants born in the state of Victoria, Australia. Three cohorts of EP/ELBW infants have been born since the introduction of surfactant to the state in 1991 and have been enrolled in the Victorian Infant Collaborative Study projects; these cohorts comprise all consecutive EP or ELBW live births born anywhere in the state during the calendar years (i) 1991-1992, (ii) 1997, and (iii) 2005. Over this time, there have been only four neonatal intensive care units in the state, three of which are located in highrisk maternity hospitals. Details of perinatal data and survival rates for these cohorts have been reported elsewhere (16-21). Small for gestational age was defined as a birth weight SD score $<-2$ SD.

\section{Measurements}

Gestational age was assigned by the best available obstetric estimate, based on antenatal ultrasound scan before $20 \mathrm{wks}$ in most cases, or menstrual history. In Victoria, $97 \%$ of women have at least one antenatal ultrasound, most of which occur at $<20$ wks' gestation (13). If there was a discrepancy between the best obstetric estimate of gestation and a pediatric assessment after birth of more than $2 \mathrm{wk}$, the pediatric estimate was taken to be correct. Maternal details collected included the presence or absence of an obstetric diagnosis of PE, based on new-onset hypertension (blood pressure 140/90 or higher), accompanied by proteinuria or nondependent edema. As some women were delivered outside the three high-risk maternity hospitals, it was not always possible to check clinical or biochemical details, but it was expected that the standard definition of PE (new-onset hypertension in a formerly normotensive woman, accompanied by proteinuria of $>0.3 \mathrm{~g}$ in $24 \mathrm{~h}$ +/- edema) was adhered to. The PE had to be of sufficient severity to warrant delivery of the fetus. BPD was defined as a supplemental oxygen requirement at $36 \mathrm{wks}$ PMA. Infants who died before reaching 36 wks' corrected gestation were excluded, as death was a competing risk for the outcome of BPD. 


\section{Literature Review}

To compare our data with other reports, we searched the literature for other studies relating PE to the incidence of BPD in preterm subjects born after 1990. PubMed and Medline were searched using the MESH terms "preeclampsia," "maternal hypertension," or "pregnancy induced hypertension," combined with "bronchopulmonary dysplasia" or "chronic lung disease." Relevant studies were selected and their references were reviewed to find further relevant studies. We sought studies where BPD was defined as oxygen dependency at 36 wks' PMA in a complete cohort with the denominator being those known to be alive at $36 \mathrm{wks}$. The search yielded seven studies that were examined in detail (6-12).

\section{Data Analysis}

Data were analyzed using SPSS for Windows, version 19, calculating ORs and 95\% CIs for differences in dichotomous variables, and calculating mean differences and 95\% CIs for comparisons of continuous variables. We also used logistic regression to adjust for the effects of antenatally determined variables that were statistically significant on univariable analysis for the relationship between PE and BPD. Postnatal variables (such as surfactant therapy, duration of ventilation, etc.) could be along the causal pathway between PE and BPD and hence were not included as confounding factors for our analysis. RevMan 5.0 was used to calculate ORs and 95\% CIs for data pooled from several studies; fixed-effects models were used for pooled ORs if there was no substantial heterogeneity and randomeffects models were used if there was moderate heterogeneity or more $\left(I^{2}>30 \%\right)(22)$.

\section{Ethics Statement}

These Victorian Infant Collaborative Study projects have all been approved as audits by the Human Research Ethics Committee at the Royal Women's Hospital.

\section{PARTICIPANTS OF THE VICTORIAN INFANT COLLABORATIVE STUDY GROUP}

Convenor: Lex W. Doyle. ${ }^{17,8}$ Collaborators (in alphabetical order): Peter J. Anderson, ${ }^{7}$ Catherine Callanan, ${ }^{1}$ Elizabeth Carse, ${ }^{3}$ Margaret P. Charlton, ${ }^{3}$ Mary-Ann Davey, ${ }^{6}$ Noni Davis, ${ }^{1}$ Cinzia de Luca, ${ }^{1}$ Julianne Duff, Marie Hayes, ${ }^{3}$ Rod Hunt, ${ }^{4}$ Esther Hutchinson, Elaine Kelly, ${ }^{1,2}$ Marion McDonald, ${ }^{1}$ Gillian Opie, ${ }^{2}$ Gehan Roberts, ${ }^{1,4}$ Michael Stewart, ${ }^{1,4}$ Linh Ung, ${ }^{1}$ Andrew Watkins, ${ }^{2}$ Amanda Williamson, ${ }^{2}$ Heather Woods. ${ }^{2}$

'Royal Women's Hospital, Melbourne; ${ }^{2}$ Mercy Hospital for Women, Melbourne; ${ }^{3}$ Monash Medical Centre, Melbourne; ${ }^{4}$ Royal Children's Hospital, Melbourne; ${ }^{5}$ Newborn Emergency Transport Service, Melbourne; ${ }^{6}$ Victorian Perinatal Data Collection Unit, Melbourne; ${ }^{7}$ Murdoch Childrens Research Institute, Melbourne; and ${ }^{8}$ University of Melbourne, Melbourne, Australia.

\section{STATEMENT OF FINANCIAL SUPPORT}

This work was supported by grants from the National Health and Medical Research Council of Australia (Project Grants 32829 and 454413) and by the Department of Innovation, Industry and Regional Development (Victorian Government).

\section{REFERENCES}

1. Sibai BM. Diagnosis and management of gestational hypertension and preeclampsia. Obstet Gynecol 2003;102:181-192.

2. Ness RB, Roberts JM. Heterogeneous causes constituting the single syndrome of preeclampsia: a hypothesis and its implications. Am J Obstet Gynecol 1996;175:1365-70.
3. Goldenberg RL, Rouse DJ. Prevention of premature birth. N Engl J Med 1998;339:313-20.

4. Roberts D, Dalziel S. Antenatal corticosteroids for accelerating fetal lung maturation for women at risk of preterm birth. Cochrane Database Syst Rev 2006;3:CD004454.

5. Soll RF. Surfactant treatment of the very preterm infant. Biol Neonate 1998;74:Suppl 1:35-42.

6. Akram Khan M, Kuzma-O’Reilly B, Brodsky NL, Bhandari V. Site-specific characteristics of infants developing bronchopulmonary dysplasia. J Perinatol 2006;26:428-35.

7. Bose C, Van Marter LJ, Laughon M, et al.; Extremely Low Gestational Age Newborn Study Investigators. Fetal growth restriction and chronic lung disease among infants born before the $28^{\text {th }}$ week of gestation. Pediatrics 2009;124:e450-8.

8. Hansen AR, Barnés CM, Folkman J, McElrath TF. Maternal preeclampsia predicts the development of bronchopulmonary dysplasia. J Pediatr 2010;156:532-6.

9. Kim CR, Vohr BR, Oh W. Effects of maternal hypertension in very-lowbirth-weight infants. Arch Pediatr Adolesc Med 1996;150:686-91.

10. Korhonen P, Tammela O, Koivisto AM, Laippala P, Ikonen S. Frequency and risk factors in bronchopulmonary dysplasia in a cohort of very low birth weight infants. Early Hum Dev 1999;54:245-58.

11. Redline RW, Wilson-Costello D, Hack M. Placental and other perinatal risk factors for chronic lung disease in very low birth weight infants. Pediatr Res 2002;52:713-9.

12. Wolf EJ, Vintzileos AM, Rosenkrantz TS, Rodis JF, Salafia CM, Pezzullo JG. Do survival and morbidity of very-low-birth-weight infants vary according to the primary pregnancy complication that results in preterm delivery? Am J Obstet Gynecol 1993;169:1233-9.

13. Yates JM, Lumley J, Bell RJ. The prevalence and timing of obstetric ultrasound in Victoria 1991-1992: a population-based study. Aust N Z J Obstet Gynaecol 1995;35:375-9.

14. Duley L. The global impact of pre-eclampsia and eclampsia. Semin Perinatol 2009;33:130-137.

15. Arnold CC, Kramer MS, Hobbs CA, McLean FH, Usher RH. Very low birth weight: a problematic cohort for epidemiologic studies of very small or immature neonates. Am J Epidemiol 1991;134:604-13.

16. The Victorian Infant Collaborative Study Group Improved outcome into the 1990s for infants weighing 500-999g at birth. Arch Dis Child Fetal Neonatal Ed 1997;77:F91-94.

17. The Victorian Infant Collaborative Study Group. Outcome at 2 years of children 23-27 weeks' gestation born in Victoria in 1991-92. J Paediatr Child Health 1997;33:161-165.

18. Doyle LW; Victorian Infant Collaborative Study Group. Outcome at 5 years of age of children 23 to 27 weeks' gestation: refining the prognosis. Pediatrics 2001;108:134-41.

19. Doyle LW; Victorian Infant Collaborative Study Group. Evaluation of neonatal intensive care for extremely low birth weight infants in Victoria over two decades: I. Effectiveness. Pediatrics 2004;113(3 Pt 1):505-9.

20. Doyle LW; Victorian Infant Collaborative Study Group. Neonatal intensive care at borderline viability-is it worth it? Early Hum Dev 2004;80:103-13.

21. Doyle LW, Roberts G, Anderson PJ. Outcomes at age 2 years of infants $<28$ weeks' gestational age born in Victoria in 2005. J Pediatr 2010;156: 49-52 e41.

22. Higgins JPT, Green S (updated September 2009). Cochrane Handbook for Systematic Reviews of Interventions version 5.0.2. The Cochrane Collaboration, Section 9.5.2, 2008. (http://www.cochrane-handbook.org.) 